DOI: 10.17707/AgricultForest.62.1.33

\author{
Sali ALIU, Imer RUSINOVCI, \\ Shukri FETAHU, Ludvik ROZMAN ${ }^{1}$
}

\title{
THE COMBINING ABILITY OF MAIZE (ZEA MAYS L.) INBRED LINES FOR GRAIN YIELD AND YIELD COMPONENTS
}

\begin{abstract}
SUMMARY
A full diallel cross comprising ten (10) inbred lines was studied for different characters to determine the nature of gene action in parents and hybrid genotypes. The analysis of variance revealed significant differences for general combining ability (GCA) and specific combining ability (SCA) indicated the presence of additive as well as non-additive gene effects for controlling the traits. However, relative magnitude of these variances indicated that additive gene effects were more prominent for all the characters studied except grain yield/plant. The ratio of the components revealed that the magnitudes of SCA components were much higher than that of GCA in all crosses except number of kernel row per ear. A wide range of variability of GCA effects was observed among the parents. For grain yield (GY) parents L2, L5, L6, L7 and L9, showed significant positive GCA effect. Thirteen five crosses exhibited significant positive SCA effects for grain yield (GY).These crosses involved high $\times$ high, high $\times$ low and low $\times$ low general combining parents (GCA). Although the cross L6 $\times$ L10 involved low $\times$ high general combiners, exhibited the highest significant positive of SCA effect $\left(14.14\right.$ tha $\left.^{-1}\right)$. The cross L1 $\times$ L10 involved the two inbreed lines with lower general combiners and also showed the lower SCA effects $\left(7.61\right.$ tha $\left.^{-1}\right)$.
\end{abstract}

Keywords: Combining abilities, GCA, gene effects, maize, SCA Abbreviations: GCA-general combining ability; SCA-specific combining ability

\section{INTRODUCTION}

The information on general combining ability (GCA) and specific combining ability (SCA) is important for hybrid development. Combining ability study of inbreeds and populations are important for hybrid breeding in order to understand the heterotic patterns of the germplasm. Many procedures have been used by plant breeders in attempt to increase the yield of maize (Geadelmann and Peterson, 1980; Aliu et al, 2008). The improvement of maize yields depends on the knowledge of the type of the gene action involved in its inheritance and also the genetic control of the related traits such as capacity of production (Rezaei et al., 2004). Grain yield of maize is a complex trait. It includes a number of

\footnotetext{
${ }^{1}$ Sali ALIU, (corresponding author: sali.aliu@uni-pr.edu), University of Prishtina, Faculty of Agriculture and Veterinary, Department of Crop Science, Prishtina, KOSOVO, Ludvik Rozman, Biotechnical Faculty, University of Ljubljana, SLOVENIA.

Notes: The authors declare that they have no conflicts of interest. Authorship Form signed online.
} 
components, which are inherited in a quantitative manner (Živanovic et al., 2006). The General Combining Abilities (GCA) and Specific Combining Abilities (SCA) effects are important indicators of potential value for inbred lines in hybrid combinations. The value of GCA tends to express Differences in GCA effects have been attributed to additive, interaction of additive $\mathrm{x}$ additive, and higher-order interactions of additive genetic effects in the base population, while differences in SCA effects have been attributed to dominant and epistatic gene effects (Spitko et al, 2010). Non additive gene effects for grain yield were found to be significant in maize (Kalla et al., 2001) which suggested that several combinations among parental lines by their mean performance and genetic nature had the potential for the development of more yielding and earlier genotypes. Evaluation of crosses among inbred lines is an important step towards the development of hybrid varieties in maize (Hallauer, 1990). This process ideally should be through evaluation of all possible crosses (diallel crosses), where the merits of each inbred line can be determined. Diallel crosses have been widely used in plant breeding to investigate combining abilities of the parental lines in order to identify superior parents for use in hybrid development programmes. Diallel mating design has been devised, also, in genetic research to investigate the inheritance of important traits among a set of genotypes and gene effects (Malik et al., 2005). Diallel crosses have been used in genetic research to determinate the inheritance of a trait among a set of genotypes and to identify superior parents for hybrid or cultivar development (Weikai Yan \& Manjit Kang, 2003). Combining ability has been investigated by several authors in maize (Kang et al., 1995; Kim and Ayala, 1996; Betrán et al., 2002; Bhatnagar et al., 2004; Glover et al., 2005). The main objective of our study was to estimate General combining ability (GCA) and Specific combining ability (SCA) among these maize inbred lines and, consequently, to identify superior single-cross hybrids $(\mathrm{SCH})$ developed from them.

\section{MATERIAL AND METHODS \\ Plot Layout and Stand Establishment}

Plant materials used as parents for crosses in this study were 10 selected superior maize inbred lines (Parents) (L1, L2, ...L10) with medium maturity, originating from the Agriculture University of Tirana, Albania. Crosses among these inbred lines were based on a diallel. During the first 3 years, we evaluated adaptability of inbred lines to specific agro-ecological conditions of Kosovo, in the locality Ferizaj (580 m a.s.l). In the fourth year, we conducted diallel crosses (with 10 inbreds) following the method of Griffing (1956). The field experiments with F1 hybrids and their parents (10 diverse maize lines and their $45 \mathrm{~F} 1$ crosses) were conducted during the fifth year. The total of means of the single crosses was calculated based on formula: $T x=\frac{p(p-1)}{2}$

Whereas: Tx is a total of means of the single crosses and $p=$ number of parents 
The experiments were based on a randomized complete block design (RCBD) with three replications. The distances between plants were $60 \times 30 \mathrm{~cm}$ or 55.000 plants $^{-1}$. The experimental plots for each replication were $5.4 \mathrm{~m}^{2}$. The seeds were sowing deep $3-5 \mathrm{~cm}$. The standard agronomic practices were applied. Measurements on plot basis were recorded on the following agronomic traits: grain yield (GY) $\mathrm{t} \mathrm{ha}^{-1}$, ear length (EL) (cm), number of rows per ear (NRE), and number of kernels per row (NKR). Grain yield evaluation was performed by measurement of ears mass for each elementary plot using average sample from each replication, in order to calculate grain yield with $14 \%$ moisture. Analyses of other above mentioned traits were conducted using 10 ears per genotype from each replication.

\section{Statistical analyses}

Differences among observed individuals, within each combination, were analyzed using the mathematic model of Griffing (1956):

$$
X i j=\mu+g i+g j+s i j+e,
$$

$X i j$ - value of the progeny derived from the crossing of $i$-th female parent with $j$-th male parent

$\mu$ - grand mean,

$g i$ - the GCA effects of the $i$-th female parent,

$g j$ - the GCA effects of the $j$-th male parent,

$s i j$ - the SCA effects specific to the hybrid of the $i$-th female line and the $j$ th male line,

$e$-experimental error.

ANOVA for GCA and SCA was calculated as presented in Table 1.

Table1. Model of ANOVA for GCA and SCA according to Griffing's method 2 ( Aliu et al.,2008)

Source d.f. S.S.

\begin{tabular}{lll}
\hline GCA & $n-1$ & $\frac{1}{n+2}\left[\sum \boldsymbol{Q}_{i .}+y_{i i}-\frac{4}{n} y_{. .}^{2}\right]$ \\
SCA & $\frac{n(n-1)}{2}$ & $\sum \sum y_{i j}^{2}-\frac{1}{n+2} \sum\left(y_{i .}+y_{i i}\right)^{2}+\frac{2}{(n+1)(n+2)} y_{. .}^{2}$ \\
Error $\quad\left[\frac{n(n+1)}{2}-1\right] \times(r-1)$ & $\frac{\text { Total S.S.-Treatm.S.S.-Replic.S.S. }}{r}$
\end{tabular}

Statistical analyses package were conducted using program - MSTAT-C , version 2.10(Russell, 1996). 


\section{RESULTS AND DISCUSSION}

Analyses of variance revealed that mean square values were significant $(\operatorname{LSD} p=0.01)$ for the genotypes for all traits under study. Analysis of variances for combining ability (Table 1) revealed that both GCA and SCA variances were highly significant for all the characters studied indicating importance of additive as well as non-additive type of gene action in controlling the traits. Effect of a replication was insignificant for all analyzed traits and suggested uniformity of a soil and agronomic practice used. The ratio of the components revealed that the magnitudes of SCA components were much higher than that of GCA in all crosses except number of kernel row per ear. (Table 2).This indicated predominance of additive gene action for all the characters except kernel rows per ear (NKR). Debnath et al. (1988), Sanghi et al. (1983), Roy et al. (1998) and Das and Islam (1994) also reported predominance of non-additive gene action for grain yield in the same crop.

Table 2. Analysis of variance for combining ability of different characters in maize line

\begin{tabular}{|c|c|c|c|c|c|c|}
\hline \multirow[b]{2}{*}{$\begin{array}{l}\text { Source } \\
\text { Variation }\end{array}$} & \multirow[b]{2}{*}{ of } & \multicolumn{5}{|c|}{ Mean sum of squares } \\
\hline & & d.f & GY & EL & NRE & NKR \\
\hline Replication & & 2 & 0.23 & 0.25 & 0.02 & 0.14 \\
\hline Crosses & & 44 & $13.78^{* *}$ & $11.08 * *$ & $42.17 * *$ & $1.95^{* *}$ \\
\hline GCA & & 9 & $10.36^{* * *}$ & $15.14 * *$ & $8.75 * *$ & $21.27 * *$ \\
\hline SCA & & 44 & $74.00 * *$ & $33.95 * *$ & $47.42 * *$ & $7.95^{* *}$ \\
\hline Error & & 108 & 0.22 & 0.15 & 0.11 & 0.12 \\
\hline GCA/SCA & & & 0.14 & 0.45 & 0.18 & 2.67 \\
\hline
\end{tabular}

** Significant at $p=0.05, p=0.01$ level respectively.

The GCA effects and performance of the parents revealed that none of the parents were found to be a good general combiner for all the characters studied (Table 3). A wide range of variability of GCA effects was observed among the parents. For grain yield (GY) parents L2, L5, L6, L7 and L9, showed significant positive GCA effect and simultaneously possessed high mean value indicating that the performance of the parents could prove as a useful index for combining ability and suggesting they contributed good alleles and their importance in grain yield improvement. Roy et al. (1998) and Hussain et al. (2003) also have observed similar results. Grain Yield (GY), Ear length (EL), Number of row per ear (NRE) showed that ratio of GCA/SCA what led to conclusion that additive gene effects are importance in inheritance of this trait. El-Badawy (2013) and EL-Hosary and Elgammaal (2013) showed that the additive gene effects represented the major role in the inheritance of grain yield and other agronomic 
traits. Theoretically, additive gene effect can be fixed in pure lines, while nonadditive can be expressed in hybrids.

Table 3. Estimates of general combining ability effects (GCA) and mean performance

\begin{tabular}{|l|l|l|l|l|l|l|l|l|}
\hline & \multicolumn{2}{l}{ GY } & \multicolumn{2}{l}{ EL } & \multicolumn{2}{l}{ NRE } & \multicolumn{2}{l|}{ NKR } \\
\hline Parents & Mean & GCA & Mean & GCA & Mean & GCA & Mean & GCA \\
\hline L1 & 3.0 & -0.05 & 12.7 & 0.023 & 13.0 & -0.38 & 17.6 & $0.483 * *$ \\
\hline L2 & 3.4 & 0.095 & 13.1 & $0.038^{*}$ & 12.0 & -0.53 & 18.3 & -0.056 \\
\hline L3 & 3.1 & -0.21 & 13.2 & $0.336^{* *}$ & 12.7 & -0.74 & 19.7 & 0.078 \\
\hline L4 & 2.1 & -0.72 & 17.2 & $0.113^{* *}$ & 12.0 & -0.74 & 16.7 & -1.95 \\
\hline L5 & 4.5 & $0.14 * *$ & 14.7 & -0.91 & 14.7 & $0.424 * *$ & 24.3 & $0.144^{* *}$ \\
\hline L6 & 4.7 & $0.64 * *$ & 12.2 & -0.11 & 15.3 & $0.576^{* *}$ & 15.7 & -0.236 \\
\hline L7 & 4.8 & $0.35^{* *}$ & 18.2 & $1.122^{* *}$ & 15.3 & -0.46 & 24.0 & $2.194 * *$ \\
\hline L8 & 3.5 & -0.03 & 13.1 & $0.062^{* *}$ & 15.6 & $0.154 * *$ & 17.0 & $0.65 * *$ \\
\hline L9 & 3.3 & 0.08 & 15.2 & $0.258^{* *}$ & 13.3 & $1.062^{* *}$ & 15.3 & -1.02 \\
\hline L10 & 4.0 & -0.34 & 14.1 & -0.92 & 15.3 & $0.664 * *$ & 21.7 & -0.28 \\
\hline $\begin{array}{l}\text { LSD } \\
0.05\end{array}$ & 0.11 & & 0.02 & & 0.01 & & 0.12 & \\
\hline $\begin{array}{l}\text { LSD } \\
0.01\end{array}$ & 0.13 & & 0.04 & & 0.04 & & 0.26 & \\
\hline SE (gi) & 0.69 & & 0.91 & & 0.85 & & 2.19 & \\
\hline
\end{tabular}

*,** significant at 0.05 and 0.01 probability levels, respectively

Parents (lines) L5, L6 and L10 showed significant negative GCA for Ear length (EL) and are good contributor and can be used in maize breeding for reducing ear length. Parent (line) L7 might is useful in developing new hybrid genotypes because was characterized with high GCA values (1.122) and suggesting it contributed good alleles for ear length. The largest significant $(\mathrm{LSD} p=0.01)$ positive GCA effects for number of row per ear (NRE) were observed for the inbred lines L9 on value 1.062. Also, the other inbred lines L5, L6, L8 and L10 had the positive values but compare to line P9 the values were lower (Table 3). For number of kernels per row (NKR) was detected for L3, L5,L7 and L8 showed largest positive significant GCA effects for NKR suggesting usefulness in breeding programmes for the increase of this trait. It is the conformation of the earlier acknowledged fact that large SCA effect often includes one parent with large GCA effect and another with small GCA (Glover et al., 2005). Specific combining ability effects (SCA, effects are shown in Table 4. For grain yield generally the crosses showing significant positive of SCA 
effects also possessed high mean performance and significant negative SCA effects possessed low mean performance. This reflects that high value of the crosses indicated their potentiality. Thirteen five crosses exhibited significant positive SCA effects for grain yield (GY). These crosses involved high $\times$ high, high $\times$ low and low $\times$ low general combining parents (GCA).The average values of GY at all crosses were 10.8 tha $^{-1}$. Although the cross L6 $\times$ L10 involved low $\times$ high general combiners, exhibited the highest significant positive of SCA effect $\left(14.14\right.$ tha $\left.^{-1}\right)$. The cross L1 $\times$ L10 involved the two inbreed lines with lower general combiners and also showed the lower SCA effects $\left(7.61\right.$ tha $\left.^{-1}\right)$. The differences between these hybrid combinations were +6.53 tha $^{-1}$ or expressed in relative values was $60.46 \%$. While differences between the parents (MP) and hybrid combination $\left(\mathrm{F}_{1}\right)$ for $\mathrm{GY}$ were $\left(\mathrm{d}=\mathrm{F}_{1}-\mathrm{MP}=+7.16 \mathrm{th}^{-1}\right)$. Ivy and Hawlader (2000) also reported that good general combining parents do not always show high SCA effects in their hybrid combinations. On the contrary, Paul and Duara (1991) reported that the parents with high GCA always produce hybrids with high estimates of SCA. Roy et al. (1998) also found significant positive SCA effects in high $\times$ low general combiners. Hybrid combination L6 x L10 and L1 x L4 showed largest positive significant ( $\operatorname{LSD} p=0.01)$ SCA effect for ear length (EL), while with lower SCA effects was characterized the combination L5 xL7 $(15.9 \mathrm{~cm})$ The differences between hybrid combination L6 x L10 and L1 xL10 were $6.40 \mathrm{~cm}$ or expressed in relative values was $31.37 \%$. The differences among the parents (MP) and hybrid combination $\left(\mathrm{F}_{1}\right)$ for $\mathrm{EL}$ were $\left(\mathrm{d}=\mathrm{F}_{1}-\mathrm{MP}=+6.06 \mathrm{~cm}\right)$ (Table 4). For NRE the average values were 16.7rows/ear. With higher SCA was determined the hybrid combination L5 xL9 (higher x higher of GCA) on value 19.2 rows/ear, while on minimal values was L7 xL10 (lower $x$ higher) on value 14.3 rows/ear. The differences between combination for NRE were +4.9 rows/ear or in relative values $29.34 \%$. The differences among the parents (MP) and hybrid combination $\left(\mathrm{F}_{1}\right)$ for NRE were $\left(\mathrm{d}=\mathrm{F}_{1}-\mathrm{MP}=+2.8\right.$ rows/ear. For NKR, the crosses L6 x L10 exhibited higher significant SCA effects (45kernel/row) of the hybrid. In this crosses are involved low x low general combining parents. With low SCA was determined the combination L1 xL10 (29.5 kernel/row) and if compared this combination on L6 xL10, the differences between them are +15 $5 \mathrm{kernel} /$ row or expressed in relative values are $41.11 \%$. While the differences among the parents (MP) and hybrid combination $\left(\mathrm{F}_{1}\right)$ for NKR were $\left(\mathrm{d}=\mathrm{F}_{1^{-}}\right.$ $\mathrm{MP}=+18.67 \mathrm{kernel} / \mathrm{row})$. Aliu et al.,(2008), has studied some maize inbreed lines and from results found that it was not possible to prove the rule that inbreeds with good GCA usually had the good SCA. Results are presented in Table.4. 
Table 4. Estimates of SCA and mean performance of the maize inbreed lines

\begin{tabular}{|c|c|c|c|c|c|c|c|c|}
\hline \multirow[b]{2}{*}{ Crossing } & \multicolumn{2}{|c|}{ GY $\left(\right.$ tha $\left.^{-1}\right)$} & \multicolumn{2}{|c|}{$\mathrm{EL}(\mathrm{cm})$} & \multicolumn{2}{|c|}{ NRE (rows/ear) } & \multicolumn{2}{|c|}{ NKR(kernel/ear) } \\
\hline & Mean & SCA & Mean & SCA & Mean & SCA & Mean & SCA \\
\hline L1x L2 & 12.01 & $2.11 * *$ & 21.2 & $1.74 * *$ & 14.4 & -0.53 & 41.3 & $6.17 * *$ \\
\hline L1x L3 & 11.73 & $2.15 * *$ & 22.1 & $2.37 * *$ & 14.3 & -0.41 & 41.8 & $6.54 * *$ \\
\hline L1x L4 & 10.45 & $1.37 * *$ & 22.3 & $2.56^{* *}$ & 16.5 & $1.86^{* *}$ & 39.0 & $5.73^{* *}$ \\
\hline L1 xL5 & 13.85 & $3.91 * *$ & 22.2 & $3.6 * *$ & 17.0 & $1.14 * *$ & 41.4 & $6 * *$ \\
\hline \begin{tabular}{|l|} 
L1xL6 \\
\end{tabular} & 12.42 & $1.98 * *$ & 21.4 & $2.12^{* *}$ & 16.5 & $0.52 *$ & 40.4 & $3.12^{\mathrm{NS}}$ \\
\hline \begin{tabular}{|l} 
L1 xL7 \\
\end{tabular} & 9.00 & -1.14 & 21.1 & $0.55^{*}$ & 14.9 & 0.006 & 40.5 & $4.97 *$ \\
\hline L1 xL8 & 12.93 & $3.16^{* * *}$ & 21.8 & $2.34 * *$ & 16.1 & $0.51^{*}$ & 40.8 & $3.47^{\mathrm{NS}}$ \\
\hline L1xL9 & 11.69 & $1.81 * *$ & 19.9 & $0.25^{\mathrm{NS}}$ & 18.3 & $1.79 * *$ & 37.7 & -5.4 \\
\hline L1 xL10 & 7.61 & -1.84 & 15.9 & -2.56 & 16.0 & \begin{tabular}{|l|}
-0.11 \\
\end{tabular} & 29.5 & $2.61^{\mathrm{NS}}$ \\
\hline L2xL3 & 10.68 & $1.01 * *$ & 21.6 & $2.12 * *$ & 15.3 & $0.8^{* * *}$ & 37.4 & $4.97 *$ \\
\hline L2xL4 & 11.52 & $2.34 * *$ & 20.9 & $1.39 * *$ & 15.4 & $0.84 * *$ & 37.7 & $6.08 * *$ \\
\hline L2xL5 & 11.82 & $1.78^{* * *}$ & 20.9 & $2.34 * *$ & 16.4 & $0.67 * *$ & 39.9 & $0.09^{\mathrm{NS}}$ \\
\hline L2xL6 & 11.72 & $1.2 * *$ & 20.8 & $1.44 * *$ & 16.9 & $0.99 * *$ & 34.5 & $6.33^{* *}$ \\
\hline L2xL7 & 10.84 & $0.59 * *$ & 21.6 & $1.07 * *$ & 15.5 & $0.63 * *$ & 43.2 & $7.44 * *$ \\
\hline L2xL8 & 11.06 & $1.2^{* *}$ & 21.5 & $1.96^{* *}$ & 16.2 & $0.71 * *$ & 42.8 & $4.25^{*}$ \\
\hline L2xL9 & 12.66 & $2.67 * *$ & 21.7 & $1.87 * *$ & 17.9 & $1.57 * *$ & 37.9 & $\mid-4.39$ \\
\hline L2xL10 & 9.74 & $0.19^{\mathrm{NS}}$ & 17.0 & -1.21 & 15.8 & -0.16 & 30.0 & $1.71^{\mathrm{NS}}$ \\
\hline L3xL4 & 10.4 & $1.53 * *$ & 20.2 & $0.48^{*}$ & 16.4 & $2.01 * *$ & 34.6 & -1.25 \\
\hline L3xL5 & 11.46 & $1.73 * *$ & 20.9 & $2.08^{* *}$ & 15.9 & $0.41^{*}$ & 33.7 & $0.36^{\mathrm{NS}}$ \\
\hline L3xL6 & 9.03 & -1.2 & 20.0 & $0.37^{\mathrm{NS}}$ & 14.9 & -0.81 & 34.9 & $1.79^{\mathrm{NS}}$ \\
\hline L3xL7 & 10.9 & $1.05^{* * *}$ & 21.4 & $0.57 *$ & 15.2 & $0.57 * *$ & 38.8 & $5.07 *$ \\
\hline L3xL8 & 8.79 & $2.83 * *$ & 21.3 & $1.53^{\mathrm{NS}}$ & 15.3 & 0.08 & 40.5 & $5.01 *$ \\
\hline L3xL9 & 11.49 & $1.81^{* * *}$ & 21.5 & $1.52 * *$ & 17.5 & $1.31^{* *}$ & 38.8 & $8.57 * *$ \\
\hline L3xL10 & 10.9 & $1.65 * *$ & 21.5 & $2.72 * *$ & 15.1 & -0.62 & 43.1 & $3.14^{\mathrm{NS}}$ \\
\hline L4xL5 & 10.41 & $1.17 * *$ & 18.1 & -0.49 & 14.9 & \begin{tabular}{|l|}
-0.58 \\
\end{tabular} & 36.1 & $4.65^{*}$ \\
\hline L4xL6 & 11.96 & $2.23 * *$ & 20.6 & $1.16^{* * *}$ & 16.6 & $0.93 * *$ & 37.2 & $0.32^{\mathrm{NS}}$ \\
\hline \begin{tabular}{|l|} 
L4xL7 \\
\end{tabular} & 11.51 & $2.08 * *$ & 19.7 & -0.93 & 14.6 & \begin{tabular}{|l|}
-0.02 \\
\end{tabular} & 35.3 & $1.27^{\mathrm{NS}}$ \\
\hline \begin{tabular}{|l|} 
L4xL8 \\
\end{tabular} & 8.26 & -0.79 & 19.2 & -0.37 & 14.5 & \begin{tabular}{|l|}
-0.74 \\
\end{tabular} & 34.7 & $2.08^{\mathrm{NS}}$ \\
\hline $14 \times L 9$ & 9.45 & $0.28^{*}$ & 20.2 & $0.39^{\mathrm{NS}}$ & 16.6 & $0.41^{*}$ & 33.8 & $4.4 *$ \\
\hline L4xL10 & 10.97 & $2.22 * *$ & 19.1 & $0.57 *$ & 15.7 & \begin{tabular}{|l|}
-0.02 \\
\end{tabular} & 36.9 & $4.36^{*}$ \\
\hline L5xL6 & 12.41 & $1.82 * *$ & 19.4 & $1.02 * *$ & 16.7 & -0.79 & 39.7 & $5.06^{*}$ \\
\hline L5xL7 & 10.51 & $0.21^{\mathrm{NS}}$ & 18.7 & -0.94 & 15.0 & $0.98^{* *}$ & 37.1 & $0.03^{\mathrm{NS}}$ \\
\hline L5xL8 & 11.65 & $1.74 * *$ & 18.6 & $0.05^{\mathrm{NS}}$ & 17.4 & $1.84 * *$ & 38.3 & $2.74^{\mathrm{NS}}$ \\
\hline L5xL9 & 9.65 & -0.36 & 17.4 & \begin{tabular}{|l|}
-1.32 \\
\end{tabular} & 19.2 & $0.47^{*}$ & 34.4 & $0.51^{\mathrm{NS}}$ \\
\hline L5xL10 & 8.82 & -0.77 & 16.5 & -1.06 & 17.4 & $0.32^{\mathrm{NS}}$ & 34.6 & $0.03^{\mathrm{NS}}$ \\
\hline \begin{tabular}{|l|} 
L6xL7 \\
\end{tabular} & 12.52 & $1.72 * *$ & 22.6 & $2.22 * *$ & 16.3 & $-0.16^{\mathrm{NS}}$ & 38.4 & $1.74^{\mathrm{NS}}$ \\
\hline L6xL8 & 9.67 & $\mid-0.74$ & 19.7 & $0.31^{\mathrm{NS}}$ & 16.4 & $0.56^{* * *}$ & 36.8 & $1.62^{\mathrm{NS}}$ \\
\hline L6xL9 & 12.2 & $1.66^{* *}$ & 21.3 & $1.72 * *$ & 16.7 & $1.09^{* *}$ & 40.9 & $7.43 * *$ \\
\hline L6xL10 & 14.14 & $4.03 * *$ & 22.3 & $4.12 * *$ & 18.2 & \begin{tabular}{|l|}
-0.65 \\
\end{tabular} & 45.0 & $10.78^{* * *}$ \\
\hline L7xL8 & 12.52 & $2.4 * *$ & 21.8 & $2.38^{* *}$ & 14.9 & $0.77 * *$ & 44.5 & $6.92 * *$ \\
\hline L7xL9 & 12.47 & $2.24 * *$ & 21.6 & $0.77 * *$ & 17.2 & -1.69 & 38.6 & $2.73^{\mathrm{NS}}$ \\
\hline L7xL10 & 12.05 & $2.23 * *$ & 20.8 & $1.23^{* *}$ & 14.3 & $0.58^{* *}$ & 39.9 & $3.22^{\mathrm{NS}}$ \\
\hline \begin{tabular}{|l} 
L8xL99 \\
\end{tabular} & 11.48 & $1.63^{* *}$ & 22.2 & $2.55^{* * *}$ & 17.7 & 0.31 & 39.1 & $4.71^{*}$ \\
\hline L8xL10 & 10.47 & $1.04 * *$ & 20.5 & $1.99 * *$ & 17.0 & $0.4 *$ & 38.4 & $3.3^{\mathrm{NS}}$ \\
\hline L9xL10 & 11.04 & $1.49^{* * *}$ & 20.4 & $1.66^{* *}$ & 18.0 & $0.39^{*}$ & 37.9 & $4.47^{*}$ \\
\hline LSD 0.05 & & 0.26 & & 0.43 & & 0.38 & & 4.25 \\
\hline LSD 0.01 & & 0.34 & & 0.61 & & 0.52 & & 5.38 \\
\hline SE (gi) & & 0.13 & & 0.23 & & 0.21 & & 1.35 \\
\hline
\end{tabular}

\footnotetext{
$*$, ** significant at 0.05 and 0.01 probability levels, respectively
} 


\section{CONCLUSIONS}

From the results it was concluded that the following parental lines L5, L6 and L7 were having good general combining ability for grain yield. These parents had resulted in the production on higher values. So, these inbred lines (parents) could be used extensively in hybrid breeding program with a view to increasing the yield level. Among the crossing combination L6xL10, L1xL5, and L1xL8 were found to be good specific combiners and these line could be used for heterosis breeding programs in maize and represent a highly valuable of genetic material.

\section{ACKNOWLEDGEMENTS}

We are grateful for the financial support provided by the Norwegian University of life Sciences /UMB, Noragric, Norway and we would like to express their sincere appreciation to Professor Mensur Vegara for his continuous support.

\section{REFERENCES}

Aliu S., Fetahu Sh .,Rozman L., Salillari A. 2008. General and specific combining ability studies for leafarea in some maize inbreds in agroecological conditions of Kosovo. Acta agriculturae Slovenica. $67-73$ pp.

Aliu S.., Fetahu Sh., Salillari A.2008. Estimation of heterosis and combining ability in maize ( zeamays 1. ) for ear weight (ew) using diallel crossing method .Latvian Journal of Agronomy. N-11.7-11 pp.

Betrán, F.J, T. Isakeit and G. Odvody .2002. Aflatoxin accumulation of white and yellow maize inbreds in diallel crosses. Crop Science., 42, 1894-1901.

Bhatnagar, S., F.J. Betrán and L.W. Rooney .2004. Combining abilities of quality protein maize

Das, U.R. and M.H. Islam. 1994. Combining ability and genetic studies for grain yield and its components in maize (Zea mays L.). Bangladesh Journal of Plant Breeding. 7(2):41-47.

Debnath, S.C., K.R. Sarker and D. Singh. 1988. Combining ability estimates in maize (Zea mays L.). Annals of Agriculture Research India. 9(1):37-42.

El-Badawy MEM .2013. Heterosis and combining ability in maize using diallel crosses among seven new inbred Lines. Asian Journal Crop Science. 5(1): 1-13.

EL-Hosar A, Elgammaal A.2013. Utilization of line $\times$ tester model for evaluating the combining ability of some new white maize inbred lines. Egypt Journal Plant Breeding. 17(1): 79-72.

Falconer, D.C. 1981. An introduction to quantitative genetics 2nd edition, Longman, New York , 67-68

Geadelmann.J.L and R.H. Petereson .1980. Effects of two yield component selection procedures on maize ,Crop science volume $18: 387-390$.

Glover, M.A., D.B Willmot., L.L. Darrah, B.E. Hibbard and X. Zhu .2005. Diallel analyses of agronomic traits using Chinese and U.S. maize germplasm. Crop Science., 45, 1096-1102. 
Griffing B. 1956. Concept of general and specific combining ability in relation to diallel crossing systems. Australian Journal Biology of Science., 9, 463-493.

Hallauer, A.R. 1990. Improvements in Yield of maize hybrids, UDC 63 193-198, Zagreb

Hussain, S.A., M. Amiruzzaman and Z. Hossain. 2003. Combining ability estimates in maize. Bangladesh Journal Agricultural Research. 28(3):435-440.inbreds. Crop Science., 44 (6), 1997-2005.

Ivy, N.A. and M.S. Hawlader. 2000. Combining ability in maize. Bangladesh Journal Agricultural Research 25(3):385-392.

Kalla V., R. Kumar and A.K. Basandral. 2001. Combining ability analysis and gene action estimates of yield and yield contributing characters in maize. Crop Research Hisar.22:102-106.

Kang, M.S., Y. Zhang and R. Magari.1995. Combining ability for weevil preference of maize grain. Crop Science. 35, 1556-1559.

Kim, S.K. and S.O. Ayala .1996. Combining ability of tropical maize germplasm in West Africa II. Tropical vs Temperate x Tropical origins, Maydica, 41, 135-141.

Malik S., Malik N, Minhas T and Munir M .2004.General and specific combining ability studies in maize diallel crosses. International Journal agricultural Biology. 6 (5), 856-859.

Paul, S. K. and R. K.Duara.1991. Combining ability studies in maize (Zea mays L.). International Journal tropics and Agriculture. 9(4): 250-254.

Rezaei A et al .2004. Estimate of heterosise and combining ability in maize (zea mays L.), Genetic Variation for plant breeding, 395-398, Vienna.

Roy, N.C., S.U. Ahmed. A. S. Hussain and M. M. Hoque. 1998. Heterosis and combining ability analysis in maize (Zea mays L.). Bangladesh J. Pl. Breed. Genet. 11(172):35-41.

Russel, D. 1996. MSTAT-C, version 2.10 Michigan State University

Sanghi, A.K., K.N. Agarwal and M.I. Qadri.1983. Combining ability for yield and maturity in early maturity maize under high plant population densities. Indian Journal of genetics.43:123-128.

Weikai Y.,Manjit Kang .2003.GGE Biplot Analysis ,207-228,New York.

Živanovic, T., S. Vuckovic, S. Prodanovic and G. Todorovic .2006. Evaluation of inbred lines as sources of new alleles for improving elite maize hybrid. Cereal Reserach. Communication. 34 (1), 941-948. 